\title{
On the advection of upwelled water on the western Yucatan Shelf
}

\section{Jorge. A. Kurczyn ${ }^{1}$, Rodrigo Duran ${ }^{2,3}$, Emilio Beier ${ }^{4}$, and Alejandro J. Souza ${ }^{5}$}

${ }^{1}$ Cátedras CONACyT-Instituto Epomex, now at Laboratorio de Ingeniería y Procesos Costeros, Instituto de Ingeniería, Universidad Nacional Autónoma de México, Sisal, Yucatán 97356, México

$4{ }^{2}$ National Energy Technology Laboratory Support Contractor, Albany, OR 97321, USA

${ }_{5}^{3}$ Thesis Research, San Diego, CA 92037, USA

$6{ }^{4}$ Centro de Investigación Científica y de Educación Superior de Ensenada (CICESE), Unidad La Paz, Laboratorio de Macroecología Marina, La Paz, Baja California Sur 23050, México

${ }^{5}$ Centro de Investigación y Estudios Avanzados del Instituto Politecnico Nacional (CINVESTAV), Km 6 antigua Carr. Mérida - Progreso, Mérida, Yucatán 97310, México

Corresponding author: J.A. Kurczyn (jkurczynr@iingen.unam.mx)

Keywords: (1) Upwelling events (2) Shelf processes (3) In-situ observations (4) Climatological Lagrangian Coherent Structures

A FREE, UPDATED, PEER-REVIEWED VERSION OF THIS PAPER CAN BE FOUND AT https: //www.frontiersin.org/articles/10.3389/fmars.2021.723452/full

\section{${ }_{15}$ Abstract}

Upwelling events over the Yucatan shelf are physical phenomena of importance for the region. In July 2018, based on oceanographic sampling, we detected the presence of upwelled waters on the west side of the shelf. These events have been widely studied on the northern Yucatecan coast but little has been said about their existence off Campeche, although they are known to the fishing communities of the region. Back-in-time Lagrangian simulations identify the origin of the subsurface Caribbean water; this particular event came from the northeast of Yucatan, over $500 \mathrm{~km}$ away from the sampling site. It took over a month to arrive at the study region, traveling alongshelf with an average velocity of $14.5 \mathrm{~cm} / \mathrm{s}$ along the region with the most intense upwelling of the Yucatan shelf. This phenomenon separated the water column into two layers with differentiable thermohaline characteristics. These trajectories are also observed with climatological Lagrangian Coherent Structures suggesting recurrence. Monthly-averaged SST anomalies also show that advected upwelling waters off Campeche occur mainly during summer (from July to August each year). 


\section{Introduction}

Located on the southeast Gulf of Mexico (GoM), the Yucatan Peninsula continental shelf (hereafter Yucatan Shelf), is an important economic area rich in fishing resources, gas, and oil deposits. It is a wide shallow marine region where the ocean floor frictions the ocean currents and detriments the height of the waves, characterized by low speeds (mean $-20 \mathrm{~cm} / \mathrm{s}$, (Martínez-López and Pares-Sierra, 1998), (Ruíz-Castillo et al., 2016)) and low significant wave heights (0.63 $\mathrm{m}$ on average), respectively. Wind stress forcing and bottom friction are the main drivers of the ocean currents over the shelf, but also the water column stratification has been found to be an important factor ((Ruíz-Castillo et al., 2016), (Reyes-Mendoza et al., 2016), (Jouanno et al., 2018)). Winds blow preferentially towards the west all year-round (also known as easterlies or trade winds), forcing the ocean to produce a westward circulation ((Martínez-López and Pares-Sierra, 1998) and (Zavala-Hidalgo et al., 2003)). But from September to June atmospheric cold fronts coming from continental North America motivate wind burst episodes affecting the region with northwesterly winds blowing over the hole GoM (events locally known as "Nortes")(Kurczyn et al., 2020).

The Yucatan Shelf, also known as the Campeche Bank, is situated in a tropical region with an abundant amount of precipitation where the karst nature of its geology causes rainwater to be absorbed by the ground, leaving almost no rivers on its surface overflowing to the sea but to the west of the peninsula. Then, continental freshwater inputs are carried through coastal lagoons and the subsoil, by water holes scattered along the seabed on the northern coast ((Herrera-Silveira et al., 2002), (Valle-Levinson et al., 2011), (Enriquez et al., 2013)), causing the salinity in most of the shelf to be influenced mainly by evaporation processes. On the other hand, the oceanographic region that surrounds this bank is very dynamic, to the east, the western arm of the large North Atlantic Anticyclonic Ocean Gyre is found represented by the strong high-speed flow of the Yucatan current. To the north, the Lazo current with its mesoscale eddies are located, and to the west is the Bay of Campeche, identified as a deep-sea area with a semi-permanent cyclonic eddy. The exchange of properties between the adjacent ocean and the shelf is limited due to the shallowness of the region, however, some very important and known interchanging processes occurring on the northern coast of this bank are the upwelling events ((Ruiz-Renteria, 1979), (Furnas and Smayda, 1987), (Reyes-Mendoza et al., 2019)).

Upwelling phenomena on the Yucatan shelf had always been known to the coastal fishing communities, still, it was until the mid-1960s that these were scientifically reported from hydrographic campaigns ((Cochrane, 1966), (Cochrane, 1968), (Cochrane, 1969), (Belousov et al., 1966), (Bogdanov et al., 1968), (Bessonov et al., 1971), (Bulanienkov and Garcia, 1973), (Ruiz-Renteria, 1979)). Numerous works have emerged investigating the events themselves and the mechanisms that generate them, managing to conceive different hypotheses ((Cochrane, 1966), (Ruiz-Renteria, 1979),(Furnas and Smayda, 1987), (Merino, 1997), (Ruíz-Castillo et al., 2016), (Reyes-Mendoza et al., 2016), (Jouanno et al., 2018)), nevertheless the subject is still a matter of investigation. Although the Yucatecan coast is parallel to the persistent trade winds of the region, its shallowness does not allow us to describe these phenomena using Ekman's theory itself. The most convincing hypothesis suggests that the Yucatecan upwelling is a phenomenon due to the interaction of the Yucatan current with the bathymetric configuration of the shelf break ((Furnas and Smayda, 1987), (Merino, 1997), (Jouanno et al., 2018)), which at the east of the Peninsula presents a notch that manages to introduce Caribbean water 250-m deep to the surface, which is then carried through the bottom of the shelf towards the coast where the westward currents, forced by the trade winds, redistribute it along the coast ((Ruíz-Castillo et al., 2016), (Reyes-Mendoza et al., 2016)).

This work is based on an upwelling event registered on the western coast of the shelf (off Campeche state), by a hydrographic survey that helped describe its main structural features. Our findings are complemented with numerical modeling, using climatological Lagrangian Coherent Structures from a 12-year HyCOM Gulf of Mexico simulation and satellite remote sensing, to analyze the point source and time of origin of the upwelled waters. This particular discovery illustrates the importance of the coastal current advection, in transporting for more than $500 \mathrm{~km}$ upwelled waters to the western side of the shelf where the coastline is perpendicular to the wind direction, bringing new insights and questions about these phenomena in the Yucatan Shelf. 


\section{Materials and Methods}

\section{In-situ data:}

\section{(a) Oceanographic survey}

From Jul 2017 to Jul 2018, five oceanographic surveys were conducted on small boats along the first ${ }^{\sim} 30$ $\mathrm{km}$ offshore of the western Yucatan Peninsula coast to sample the seasonal variation of the thermohaline characteristics of the coastal ocean. Each survey took about one week to be completed and was planned three months apart from each other. This particular work presents the findings of the $5^{\text {th }}$ campaign that occurred during summer 2018 (Jul 23- 28, Figure 1). The vessels used in the surveys were equipped with a hand-held Valeport miniCTD factory-calibrated, and a Garmin GPS, to collect temperature, conductivity, and depth data, at all sampling stations. These data were later transformed to observations of conservative temperature (CT) and absolute salinity (SA) using the thermodynamic equation of seawater TEOS-10 toolbox (McDougall and Barker, 2011). To show the surface distribution of SA and CT in the study region, surface samplings of these variables were optimum interpolated using the Data-Interpolating Variational Analysis software (Troupin et al., 2012). All data were processed using the R software (RCoreTeam, 2014).

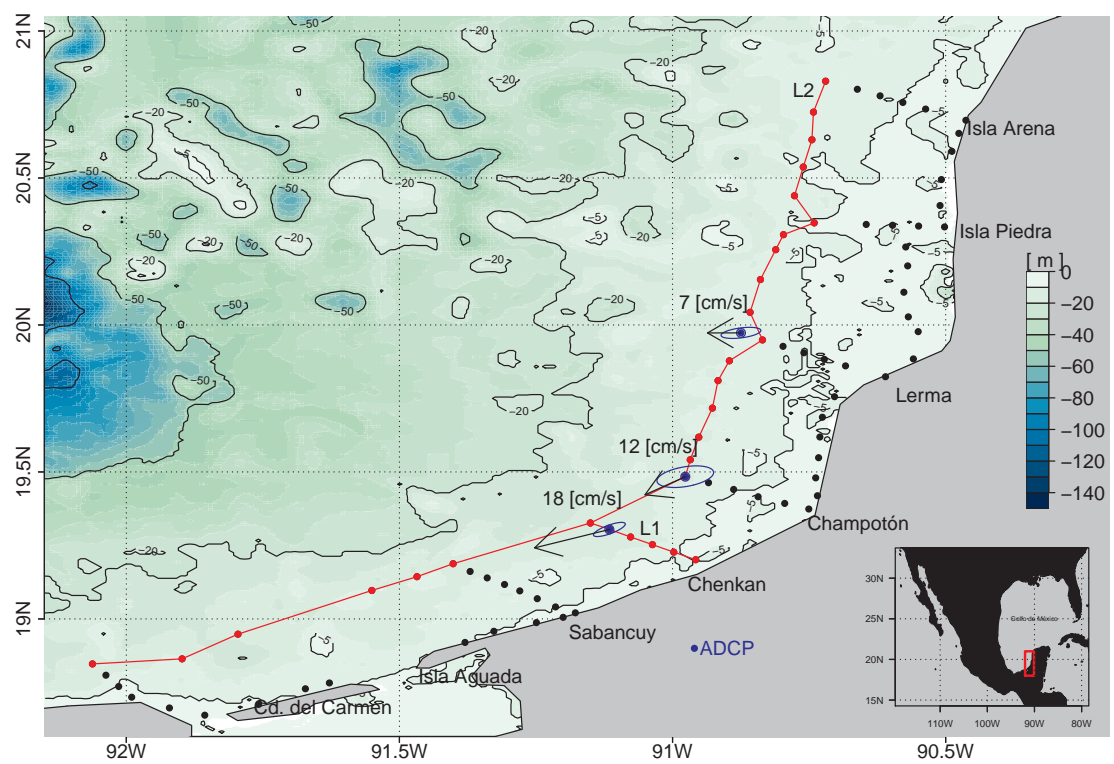

Figure 1: Study area for the oceanographic surveys (black dots) and location of the ADCPs (blue dots). Red dots show stations used to depict cross-shore (L1) and along-shore view (L2) of the hydrographic properties. Mean surface current vector and variance ellipse (in blue) during July 2018. Bathymetry is shown as a background color.

\section{(b) Acoustic Doppler Current Profiler (ADCP) observations:}

Two ADCPs were located on the western continental shelf of the Yucatan Peninsula at $\sim 11 \mathrm{~m}$ depth. These were Nortek-AWACs of $1 \mathrm{MHz}$, measuring the current profile divided into eight layers, starting $1.4 \mathrm{~m}$ above the bottom until $2.6 \mathrm{~m}$ below the surface, taking samples every $20 \mathrm{~min}$ and averaging the first $60 \mathrm{~s}$ of the observations. The ADCPs were used to measure three sites, two of these simultaneously (Table 1): 


$\begin{array}{cccc}\text { Loca- } & \text { Fixed ADCP } & \text { ADCP 2.a } & \text { ADCP 2.b } \\ \text { tion } & \text { Lerma } & \text { Champoton } & \text { Chenkan } \\ \text { Position } & 19^{\circ} 58^{\prime} 22.8 ” \mathrm{~N}, & 19^{\circ} 29^{\prime} 1.86^{\prime \prime} \mathrm{N}, & 19^{\circ} 18^{\prime} 15.48^{\prime \prime} \mathrm{N}, \\ & 90 \text { deg52'29.03"W } & \text { 90deg58'36.12"W } & 91 \mathrm{deg} 6^{\prime} 56.34 " \mathrm{~W} \\ \text { Dates } & \text { 1-Jun to } 31-J u l-2018 & \text { 1-Jun to 13-Jul-2018 } & \text { 26-Jul to 31-Jul-2018 }\end{array}$

Table 1: Positions of the ADCPs.

Tides were eliminated from the ADCP observations using a Lanczos filter with a cut-off frequency of 24 hours, leaving only the dynamic structure of the currents due to surface wind stress, bottom friction, and geostrophic forcing. In this work, only the mean currents measured during June and July 2018 were shown (Figure 1).

\section{Satellite data:}

To depict the regional distribution of the sea surface temperature, ocean currents, and winds during July 2018, the following remotely sensed data was employed:

\section{(a) Optimum Interpolation Sea Surface Temperature (OISST)}

The NOAA $1 / 4^{\circ}$ daily Optimum Interpolation Sea Surface Temperature (or daily OISST) is an analysis constructed by combining observations from different platforms (satellites, ships, buoys) on a regular global grid. A spatially complete SST map is produced by interpolating to fill in gaps. The methodology includes bias adjustment of satellite and ship observations (referenced to buoys) to compensate for platform differences and sensor biases (Reynolds et al., 2002). These data was provided by the NOAA/OAR/ESRL PSD, Boulder, Colorado, USA, from their Web site at https://www.esrl.noaa.gov/psd/.

\section{(b) Aviso+ Multimission altimeter satellite gridded sea surface heights}

Altimeter satellite gridded Sea Level Anomalies (SLA) were computed with respect to a twenty-year mean, processed by the DUACS multimission altimeter data processing system, incorporating data from all altimeter missions: Jason-3, Sentinel-3A, HY-2A, Saral/AltiKa, Cryosat-2, Jason-2, Jason-1, T/P, ENVISAT, GFO, ERS1/2. All the missions are homogenized with respect to a reference mission OSTM/Jason-2. The SLA is computed with an optimal and centered computation time window (6 weeks before and after the date). Resolution is $0.25 \times 0.25$ degrees and has an irregular temporal resolution, although they are distributed on a daily basis. This dataset can be downloaded from the Copernicus Marine Environment Monitoring Service (CMEMS): https://resources.marine.copernicus.eu/? option=com_csw\&task=results\&product_id=SEALEVEL_GLO_PHY_L4_REP_OBSERVATIONS_008_047\&view=details

\section{(c) ASCAT}

Daily wind and wind stress fields are estimated over global oceans from Metop/ASCAT retrievals using an objective method. The resulting fields have spatial resolutions of $0.25^{\circ}$ in longitude and latitude. The calculation of daily estimates uses ascending as well as descending available and valid retrievals. Data and documentation are freely distributed on Cersat/Ifremer FTP site (ftp://ftp.ifremer.fr/ifremer/cersat/products/ gridded/MWF/L3/ASCAT/Daily/ ). 


\section{Lagrangian simulations:}

Trajectories were integrated back in time for 40 days, from July 19 to June 10; in one experiment using the 2018 velocity from HyCOM GOM10.04 expt. 32.5, and in another experiment using the 2003-2014 HyCOM climatological velocity described in (Duran et al., 2018). The almost 7 thousand trajectories in each experiment were computed using a fourth-order Runge-Kutta with cubic interpolation, a combination that has been shown to be efficient and accurate when integrating discrete data (Nordam and Duran, 2020). The 2018 velocity was a two-dimensional field at 5 meters depth, while the climatological velocity is a surface field.

\section{Climatological Lagrangian Coherent Structures}

Climatological Lagrangian Coherent Structures (cLCS) were developed in (Duran et al., 2018) to identify persistent or recurrent Lagrangian transport patterns. The instantaneous trajectories in this paper are compared with the Gulf of Mexico cLCS computed in (Duran et al., 2018). The code for cLCS is described and freely available (Duran et al., 2019); the climatological velocity (with which the results of (Duran et al., 2018) can be replicated) is also available at that repository.

cLCS differ from typical Lagrangian Coherent Structures (LCS) in that the Cauchy-Green tensor is averaged over different initial times, and that the time-dependant velocity is a climatological velocity. Regarding the climatological averaging, it is shown in the first section of the results in (Duran et al., 2018), that the Eulerian climatological velocity preserves the main Lagrangian circulation in an ensemble-mean sense, where ensemble averaging of the instantaneous trajectories is over different initial times. However, the averaging of the Cauchy-Green tensor formally destroys the transport-barrier property of LCS (Haller, 2015). Thus, the interpretation of cLCS requires careful comparison with additional Eulerian and Lagrangian information, as for example described in (Gouveia et al., 2021) where it is shown that cLCS may deform as chevrons. When cLCS deform as chevrons, they do not represent transport barriers, but instead, they identify a jet-like structure, as is the case in this paper where cLCS identify a coastal jet-like current. However, depending on the local circulation, cLCS may also indicate persistent and efficient transport barriers ((Duran et al., 2018), (Gough et al., 2019)) or recurrent attractive pathways ((Duran et al., 2018), (Maslo et al., 2020)). The different interpretations for cLCS follow the fact that CLCS can be thought of as a superposition of 7-day LCS from the climatological velocity, with the integration initiating at different times (see e.g. Appendix C of (Duran et al., 2018)). In the Supporting Information (Appendix A) of (Duran et al., 2018), it is shown that the deformation due to along-path horizontal divergence is negligible and therefore the patterns identified by cLCS are due to large-scale two-dimensional flow (see also supporting information in (Gouveia et al., 2021)).

\section{Results}

\section{In-situ and remote observations:}

The Yucatan shelf is a shallow environment defined by a very smooth slope, $1 \mathrm{~m} / 3000 \mathrm{~m}$ off Campeche and $1 \mathrm{~m} / 1000 \mathrm{~m}$ off Yucatan, where the mobility of the vessels is limited by draft restrictions. In this work, the sampling stations of the surveys fell on depths ranging between 2 to $20-\mathrm{m}$ depth, capturing the thermohaline variations of the first $\sim 30 \mathrm{Km}$ of the coast. Figure 2 depicts the $\mathrm{T} / \mathrm{S}$ diagram of the campaign, where two water types were found: (1) Caribbean Tropical Surface Water (CTSW), also called Yucatan Seawater (off Yucatan state, (Enriquez et al., 2013)) or Gulf Common Water (off the GoM west coast, (Vidal et al., 1994)), and (2) Caribbean Subtropical Under Water (CSUW). The former occupied most of the study region, 
presenting a modification of the CTSW having saltier values than the reported for the region ((Nowlin and Mclellan, 1967), (Vidal et al., 1994), (Merino, 1997), (Aldeco et al., 2009), (Enriquez et al., 2013)). Waters located in the first $5 \mathrm{~m}$ showed very warm temperatures $\left(29.6 \pm 1{ }^{\circ} \mathrm{C}\right)$ with large salinity and density ranges, influenced mainly by evaporation processes between the lower atmosphere and the surface ocean, and to a lesser extent by nearshore freshwater inputs from the Champoton river, coastal lagoons, and submarine groundwater discharges located near the coast, particularly in the northern part of the study area between Lerma and Isla Arena $\left(20-21^{\circ} \mathrm{N}, 91^{\circ} \mathrm{W}\right)$.

On the other hand, water temperatures below $26{ }^{\circ} \mathrm{C}$ were seen between 7 to $16-\mathrm{m}$ depth, located on the farthest sampling stations to the shore. At these depths, saltier Caribbean Subtropical Under Water-type signature was found. This water is commonly found in the Yucatan Channel at 250-m depth, and its presence over the Yucatan shelf is attributed to upwelling processes between the Yucatan current and bottom friction on the northeastern side of the Yucatan Peninsula ((Merino, 1997), (Jouanno et al., 2018)), approximately $600 \mathrm{Km}$ to the east from the study region. This result illustrated a two-layer distribution of coastal waters on the deepest parts of the study region, represented by the CTSW above the CSUW, with local processes (evaporation/freshwater inputs) modifying their characteristics. It was found that evaporation processes greatly exceeded precipitation (or freshwater inputs) as both water types showed saltier values, even though the survey was carried in July which is at the middle of the rainy season defined from May to November.

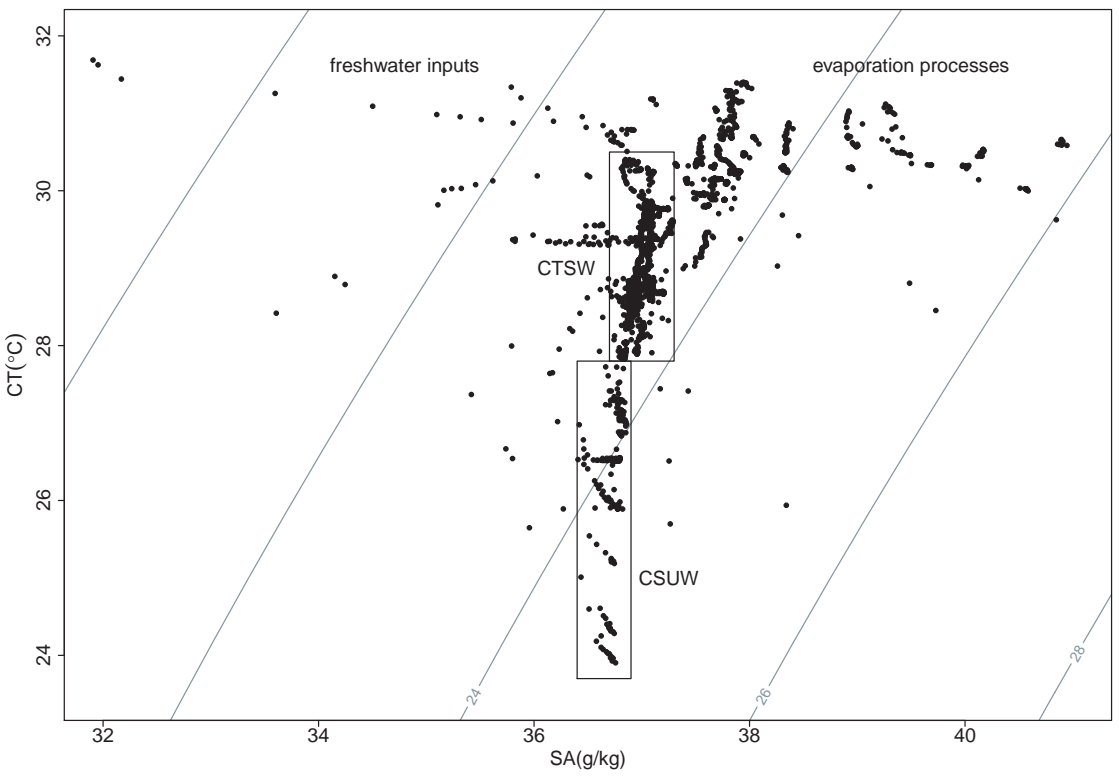

Figure 2: Temperature (Conservative Temperature) and Salinity (Absolute Salinity) diagram for July 2018. Water type signatures found during this survey are: (1) The CTSW- Caribbean Tropical Surface Water, and (2) the CSUW-Caribbean Subtropical Under Water. Contours represent $\sigma \theta$ values.

Figure 3 depicts the surface salinity and temperature distribution during the days of the survey, which represents an approximate 6-day average. It exhibited salty and warm values all along the coast, particularly between Lerma and Isla Piedra which are located on the shallowest depths $(<5 \mathrm{~m})$ at the NE of the study region. At the northwestern edge of the sampling region (off Isla Arena), upwelled waters coming from the Yucatan coast entered the study area bringing "cold" temperatures and mild salinities $\left(27^{\circ} \mathrm{C}\right.$ and 37.2 $\mathrm{g} / \mathrm{Kg}$, respectively). Off Terminos lagoon, located on the south of the study region, flushing waters from this body of water expelled warm $\left(30^{\circ} \mathrm{C}\right)$ and less salty waters and $(36.2 \mathrm{~g} / \mathrm{Kg})$, thru its southern mouth (Boca del Zacatal) to the adjacent ocean. 


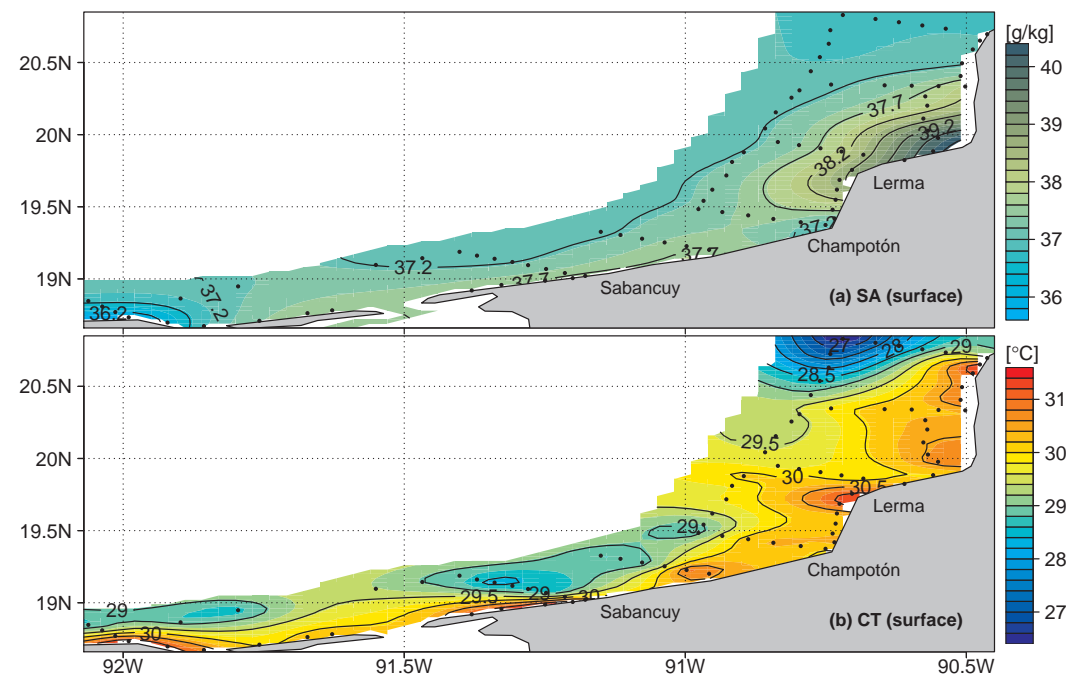

Figure 3: Surface distribution of (a) Absolute Salinity $\left(\mathrm{g} / \mathrm{Kg}\right.$ ) and (b) Conservative Temperature $\left({ }^{\circ} \mathrm{C}\right)$, optimum interpolated.

Regularly during the surveys, ADCPs were recovered for maintenance and battery replacement. Their mooring locations were planned to coincide with a particular CTD station of the survey. During summer 2018 we decided to change the Champoton ADCP further south, off Chenkan (Table 1). While positioning it on its new location, during the diving maneuver we noticed that the water column was divided into what seemed two layers of water, a wide layer of warm and clear water above a thin layer of low-visibility and cold water located very next to the ocean floor. We felt curious about this phenomenon, which was unnoticeable during the recovery of this ADCP some days before off Champoton. The CTD observations (Figure 4) illustrates the cross-shore thermodynamic distribution along the Chenkan section, where a saltier and warmer layer of water (CTSW) was located above a fresher and colder thin layer of water (CSUW), located next to the bottom of the ocean and extending for more than $15 \mathrm{~km}$ long. The CSUW water-type was located $10 \mathrm{Km}$ away from the shore at a depth between 7 to $15 \mathrm{~m}$. Very next to the shore, CTSW salinity and temperature contours showed a vertical distribution of this water-type that changed horizontally right above the location of the CSUW. The ADCP mooring was located on the CTD station before the end of the section $(\sim 25 \mathrm{~km}$ offshore). 


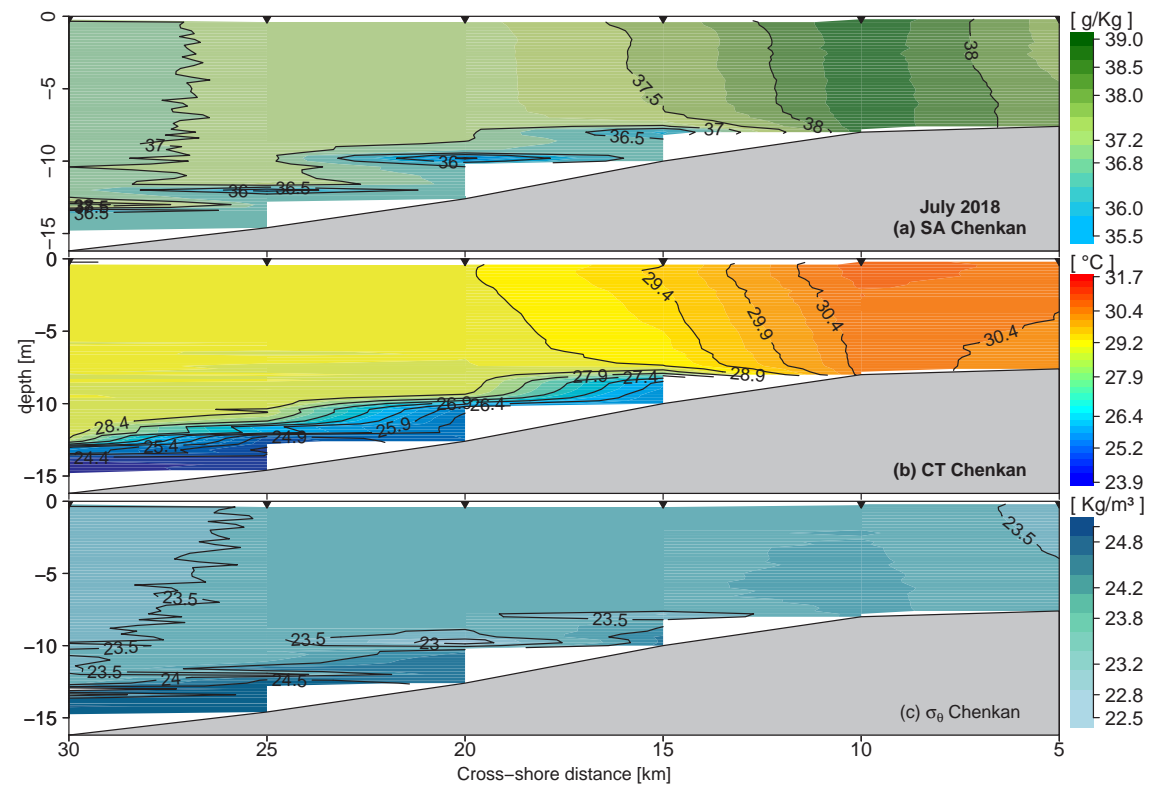

Figure 4: Cross-shore view of the vertical distribution of (a) Absolute Salinity (g/Kg), (b) Conservative Temperature $\left({ }^{\circ} \mathrm{C}\right)$, and $(\mathrm{c})$ density $\left(\sigma \theta\right.$ in $\left.\mathrm{Kg} / \mathrm{m}^{3}\right)$, off Chenkan locality ( $\mathrm{L} 1$ on Fig. 1). Black triangles on top depict sampling stations.

The vertical distribution of the upwelled CSUW along the Campeche shore was illustrated in Fig. 5. It complemented the results of Fig. 3, showing the behavior of the upwelled water in the vertical as it flows towards the southwest. It penetrated the study region off Isla Arena, then it was kept away from the sampling region from Isla Piedra to the south of Lerma (between $20-21^{\circ} \mathrm{N}, 91^{\circ} \mathrm{W}$ ) and got closer to the shore around Champoton until the rest of the region. This colder and fresher water could not reach the shore in the northern region due to a bathymetric step that disappears after passing Champoton, which prevents the approach of this water towards the coast. The upwelled water occupied the whole water column on the northern region (off Isla Arena) but passing Champoton it was restricted to a thin layer close to the ocean floor. 


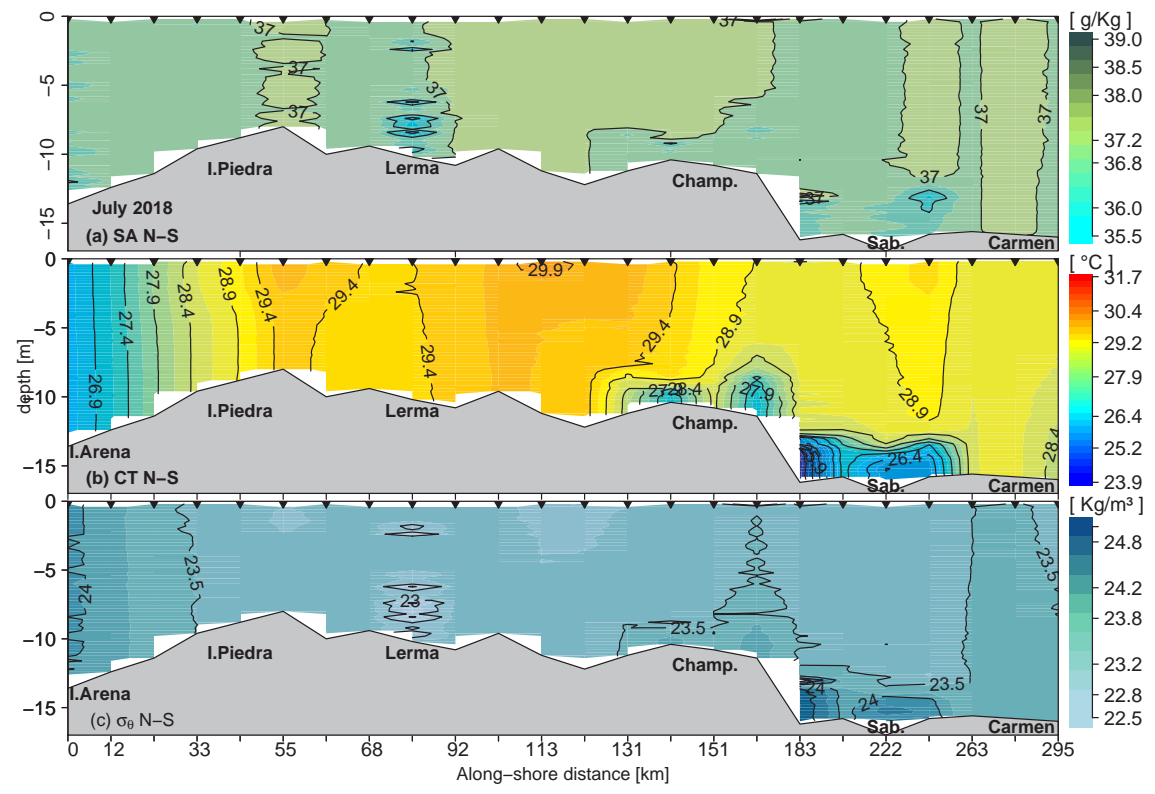

Figure 5: Along-shore view of the vertical distribution of (a) Absolute Salinity (g/Kg), (b) Conservative Temperature $\left({ }^{\circ} \mathrm{C}\right)$, and $(\mathrm{c})$ density $\left(\sigma \theta\right.$ in $\left.\mathrm{Kg} / \mathrm{m}^{3}\right)$, for sampling stations aligned from north to south (L2 on Fig 1). Black triangles on top depict sampling stations.

Remotely sensed observations were used to expand the study's spatial and temporal extent and explore the behavior of sea surface temperature (SST), currents, and winds, during the upwelling event. SST anomalies exhibited a cold tongue of seawater extending from the north-eastern coast of the Yucatan Peninsula all the way until Isla Aguada in southern Campeche, reaching a minimum SSTa during July $19^{\text {th }}$ (Fig. 6.a1). Near the coast, the bathymetric restriction off northern Campeche $\left(20-21^{\circ} \mathrm{N}, 91^{\circ} \mathrm{W}\right)$ presented warmer anomalies during all the time of the event, and it is clear that during the time of the survey (Fig. 6.c1), this phenomenon was weakening and retracting, showing smoother SSTa with positive values off Campeche and low-negative values off Yucatan. Off Campeche, currents and winds are most of the time south-westward and easterly flows, respectively, and during the dates inspected this was no different (Fig. 6.middle and lower panels). 


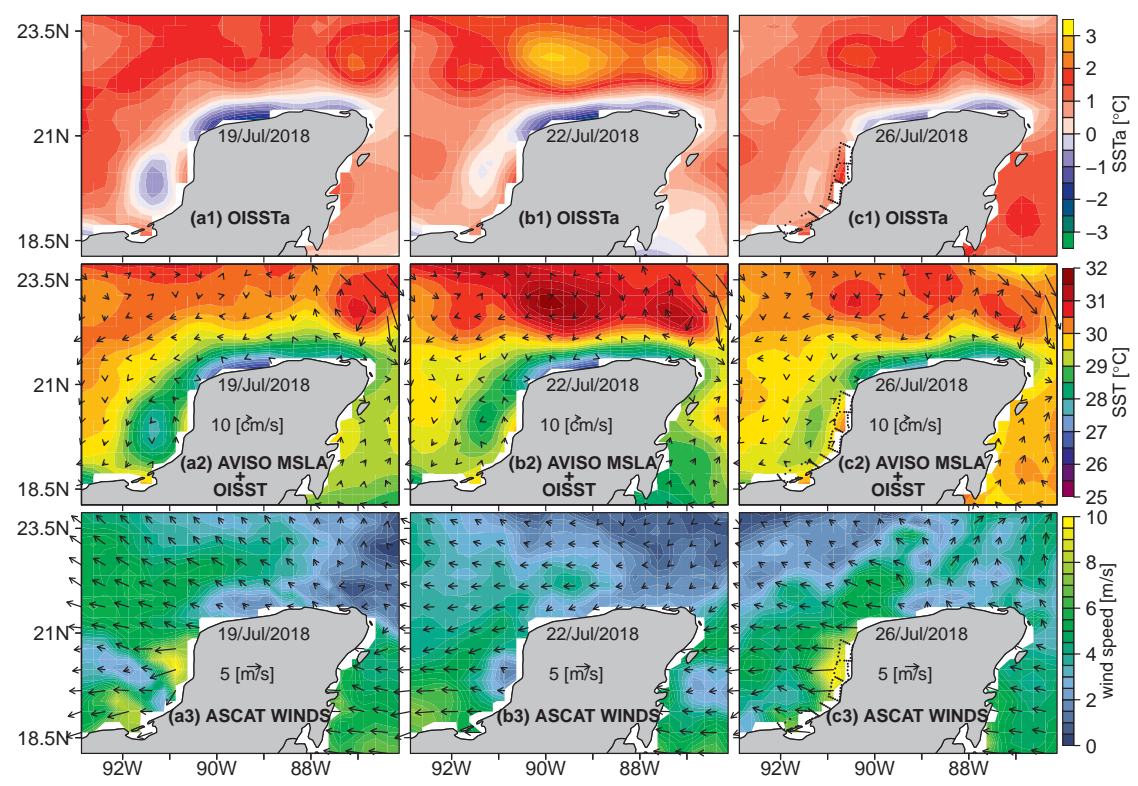

Figure 6: Satellite images of the regional distribution of (a) Sea Surface Temperature anomalies (SSTa), (b) SST plus geostrophic currents, and (c) surface winds, during the end of July 2018.

\section{Lagrangian simulations:}

Trajectories were initiated from a regular grid of initial positions with a constant spacing of 0.01 degrees within a polygon encompassing the Campeche pool of cool water as determined from satellite SST on July 19, 2018 (Fig. 7). Back-in-time trajectories indicate that the water within the polygon of initial positions mainly came from the northeast in the 2018 experiment, and only from the northeast in the climatological experiment.

Using the 2018 velocity, about $18 \%$ of all trajectories had at least one longitude to the west of the westernmost point of the initial-position polygon, and $80 \%$ of all trajectories had at least one point to the east of the easternmost point of the initial-position polygon (Fig. 7b). In the climatological experiment, in contrast, trajectories only from the Yucatan shelf to the northeast (Fig. 7d).

At the surface, SST advection by the ocean model (HyCOM) also shows cool water moving along the same path as the trajectories and along a tongue of water that is about 2-3 degrees Celsius cooler than the rest of the surface water over the Yucatan shelf (Fig. 7c). Satellite and model SST are in good agreement, although the model has additional variability as should be expected from a higher resolution simulation (Fig. 7a and $7 \mathrm{c})$. 

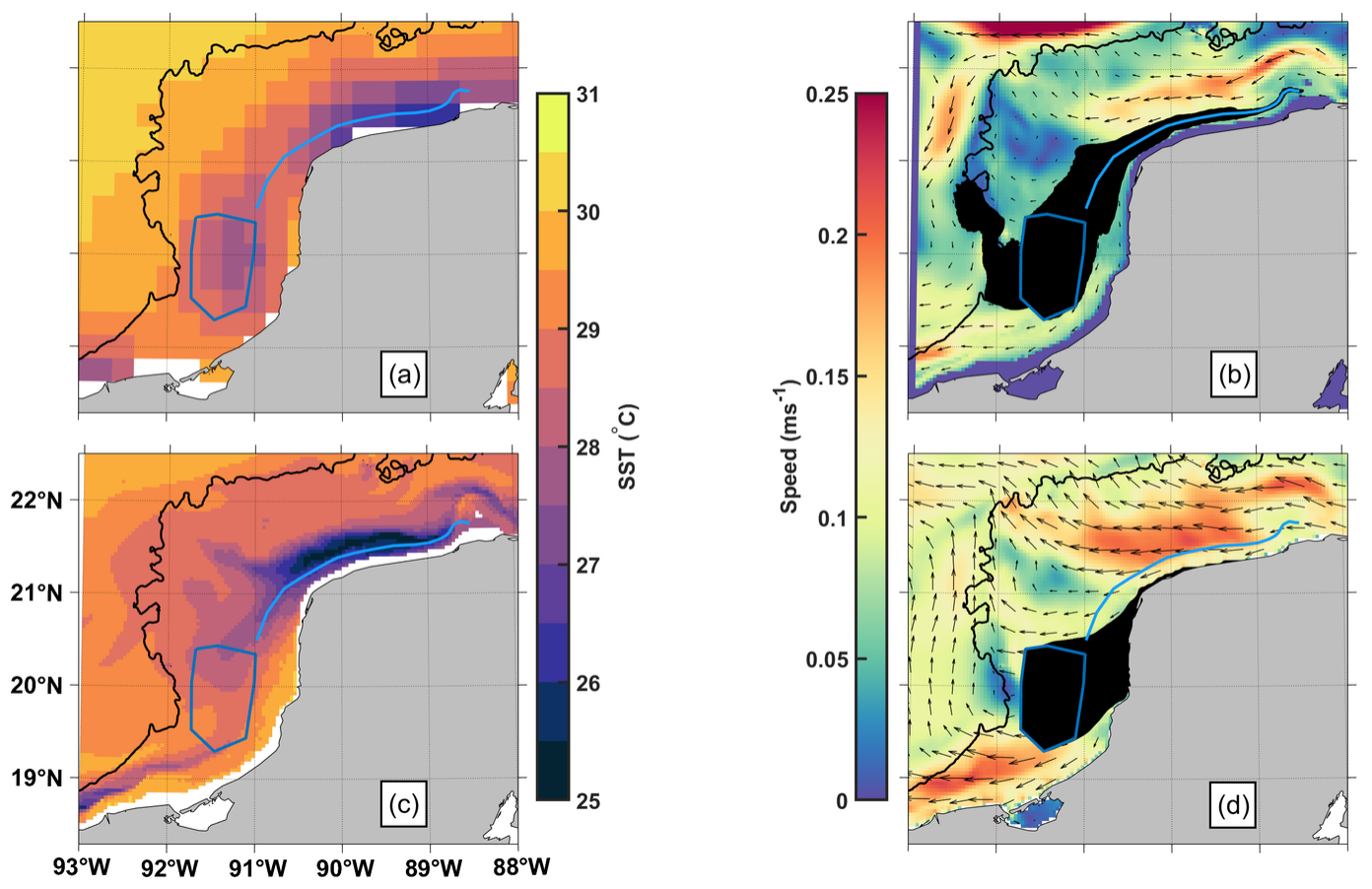

Figure 7: Sea Surface Temperature $\left({ }^{\circ} \mathrm{C}\right)$ from satellite (a) and HyCOM GoM (c) on July 19, 2018. The blue polygon is used as initial conditions for back-in-time trajectories to investigate the cool water pool's origin in the satellite data (a). Black dots in the right column are points from trajectories initiated within the blue polygon on July 19, 2018, and integrated back in time for 40 days (June 10, 2018) using HyCOM GoM's velocity at 5-m depth (b), and a 1994-2014 climatological velocity at the surface (d). Color contours in the right column are the velocity magnitude $\left(\mathrm{ms}^{-1}\right)$ used for the trajectories after time averaging, HyCOM GoM at $5-\mathrm{m}$ depth is shown in (b), and the velocity climatology at the surface is shown in (d). The blue line is used as a path representative of most of the trajectories shown in (b) and is plotted as a reference in the other panels. The 50-m isobath is shown in black. (Fig. 8).

Water parcels ending within the cool water polygon (initial-position) traverse most of their path along a region of relatively intense upwelling of about 1-4 meters per day that is present through the water column from the bottom to 5 meters deep, in the 40 days leading to the observation of the cool satellite SST pool (Fig. 8). The maxima in upward velocity along the representative horizontal trajectory coincide with the SST minima from satellite and HyCOM data (cf. Figs. 7a, 7c, and 8). 


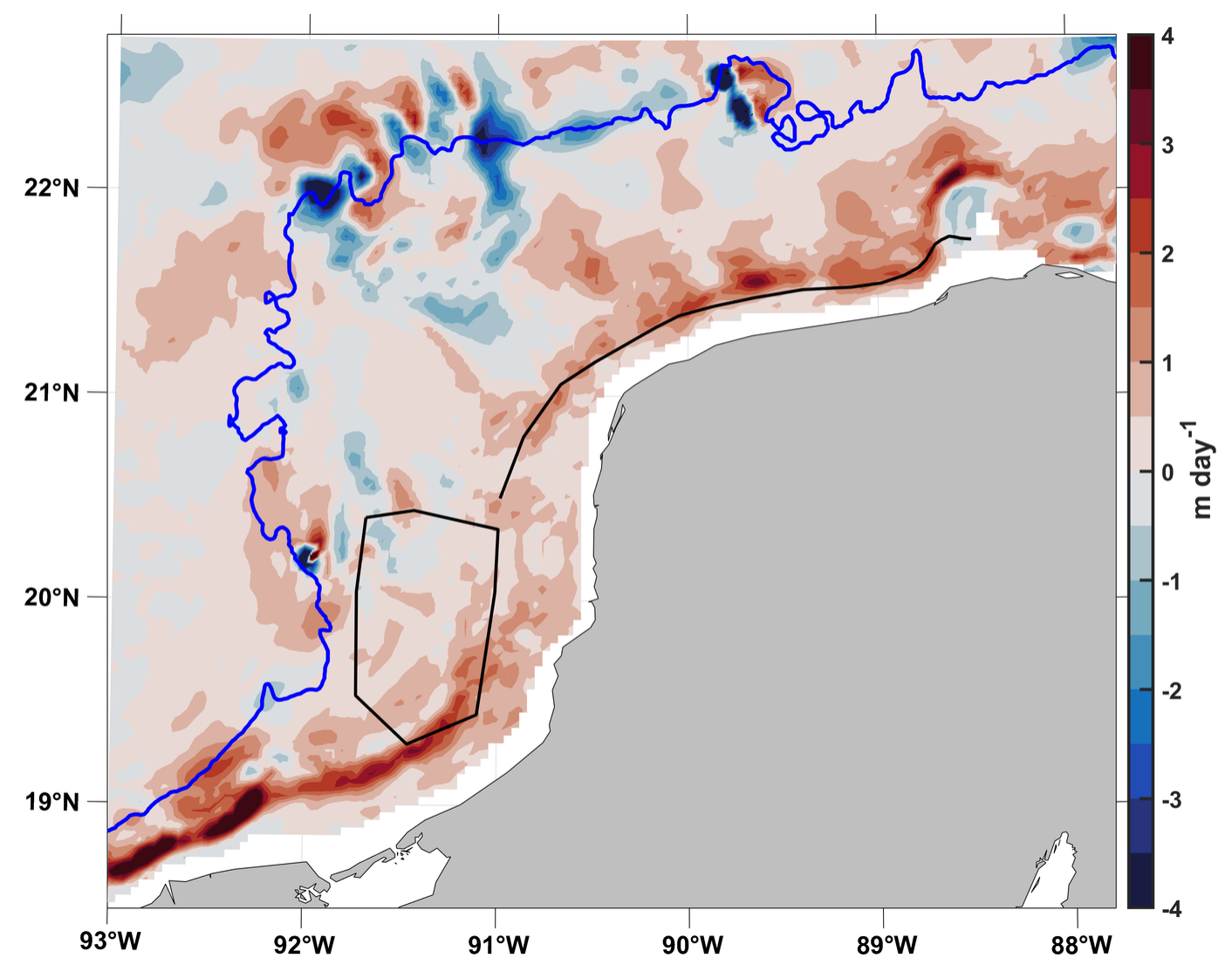

Figure 8: Vertical velocity (m/day) from HyCOM GoM, time-averaged June 10, 2018, through July 19, 2018, and depth-averaged between $5 \mathrm{~m}$ and $50 \mathrm{~m}$, or bottom when less than $50 \mathrm{~m}$. The $50-\mathrm{m}$ isobath is shown in blue; the polygon used for initial trajectory positions, and a representative trajectory, (see Fig. 7) are shown in black

There is good agreement between trajectories from the 2018 experiment computed here and cLCS from (Duran et al., 2018). Trajectories from the east move across weak cLCS that are deformed as chevrons within the Yucatan shelf, while trajectories from the northwest move along strong cLCS until they meet within the initial-position polygon (Fig. 9). The advection of cool SST coincides with most trajectories (Fig. 7c) in crossing weak cLCS that, deformed as chevrons, indicate the direction of weak transport. We note that, unlike LCS, cLCS are not proper transport barriers. The chevrons reported here are similar to what was found in (Gouveia et al., 2021), where along-slope SST advection happens through weak cLCS deformed as chevrons, while cLCS with relatively strong climatological attraction indicate transport barriers. 


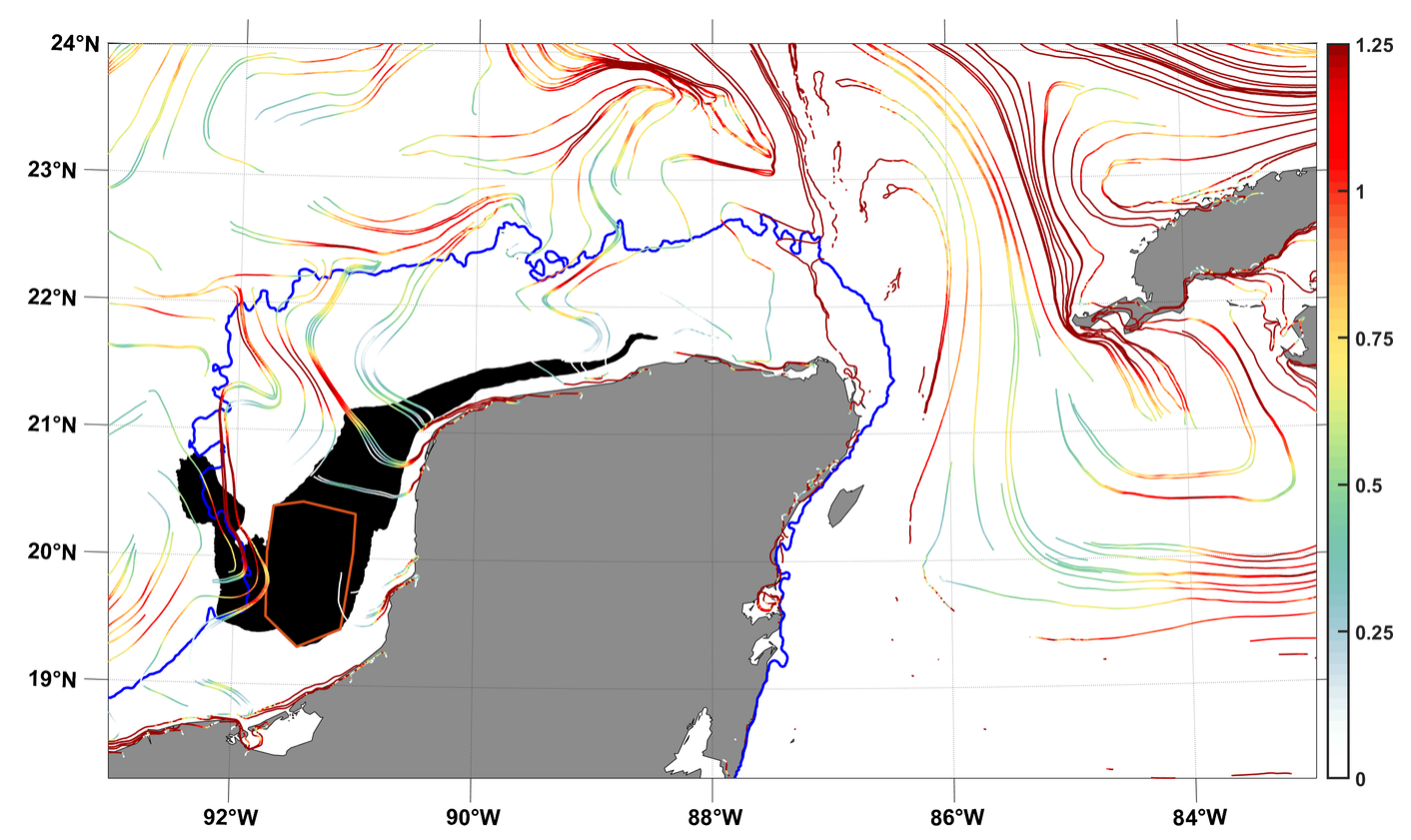

Figure 9: Climatological Lagrangian Coherent Structures (lines) colored according to their climatological strength of attraction (c $\rho$, logarithmic scale) for July. The trajectories from figure $7(\mathrm{~b})$ are plotted in black, with the polygon used for their initial positions is plotted for reference in dark orange. The 50-m isobath is show in in blue.

\section{Discussion}

The hydrographic features and the numerical simulations described here confirm the existence of upwelling waters along the western Yucatan shelf, brought from the northeast by coastal current advection. In their works of upwelling events over the northeastern Yucatecan coast, (Ruiz-Renteria, 1979), (Merino, 1997), and (Jouanno et al., 2018) proposed that local wind acts indirectly in the upwelling intensity and variability by inducing high-frequency variations in the current magnitude over the platform. Once the upwelled water intrudes the shelf from the eastern notch, the wind-forced currents spread this water along the north coast, particularly during spring and summer. Similar to their findings, (Martínez-López and Pares-Sierra, 1998) detected a wind stress-forced westward current with maximum transport in July-August ((Zavala-Hidalgo et al., 2003)). Off Campeche, more than 1.5 years of ADCP observations off Lerma and Champoton (result not shown) registered a mean $5 \mathrm{~cm} / \mathrm{s}$ southwestward surface flow with maximum velocities reaching $43 \mathrm{~cm} / \mathrm{s}$. On the other hand, considering the $500 \mathrm{~km}$ traveled by the upwelled waters in 40 days gives an averaged advected velocity of $14.5 \mathrm{~cm} / \mathrm{s}$, comparable to the westward current velocity simulations of 5-20 cm/s off Yucatan ((Martínez-López and Pares-Sierra, 1998), (Ruíz-Castillo et al., 2016)).

An interesting feature promoted by these upwelling events is the two-layer water column distribution in such an open and shallow environment, as depicted in the T/s diagram (Fig. 2). Other authors had evidenced the large spatial coverture of these events over the shelf ((Ruíz-Castillo et al., 2016)) and its lasting duration from spring to autumn ((Merino, 1997)), which had demonstrated its importance on the productivity of the bank, as Nitrate distributions of the upwelled water layer fertilize the shelf ((Furnas and Smayda, 1987), (Merino, 1997)). Despite we did not present any Nitrate data over the western side we believe upwelling events enhance its productivity, although more hydrographic evidence is needed to enlarge our understanding of 
this phenomenon on this side of the shelf and the role it may play in the seasonal and interannual variation of the regional fishing resources.

Some works have studied the seasonality of the upwelling events over the Yucatan Shelf ((Molinari, 1980), (Merino, 1997)) and attributed it to the Yucatan Current flow intensity, which strengthens during spring and summer and weakens in autumn-winter, implying bottom friction mechanisms. On the other hand, (Ruíz-Castillo et al., 2016) explored the relationship between the alongshore wind stress over the shelf and the seasonality of the upwelling events, using a Longitude-time (Hövmuller) diagram of the mean monthly upwelling index (his Fig. 9). They found upwelling events throughout the year with two strong periods: March and July and October and December, the former being stronger. To explore the regularity of the advected upwelled waters over the western coast, we analyzed the alongshore SST anomaly distribution from the Caribbean sea $\left(87^{\circ} \mathrm{W}\right)$ until the Tabasco coast $\left(>92^{\circ} \mathrm{W}\right.$, Figure 10), where cooling events are related to negative anomalies (blue color values). From the eastern side of the shelf until the western side, the Campeche coast is shown between longitudes $92-90^{\circ} \mathrm{W}$, cooling events are seen alongshore all year round. Although SST is related to different surface heat budget processes and could be noisy to attributed it solely to the upwelling events, it showed an interesting resemblance to the findings of (Merino, 1997) and (Ruíz-Castillo et al., 2016). It exhibited colder SST anomalies between July to August (in summer) off Campeche, and between April to August (spring and summer) off the Yucatecan coast. During winter (from January to March) surface cooling events encompassed all the region, from the Caribbean until Tabasco, although their SST anomalies are low and are probably related to the northerly cold wind burst events (the "Nortes") that affect all the GoM.

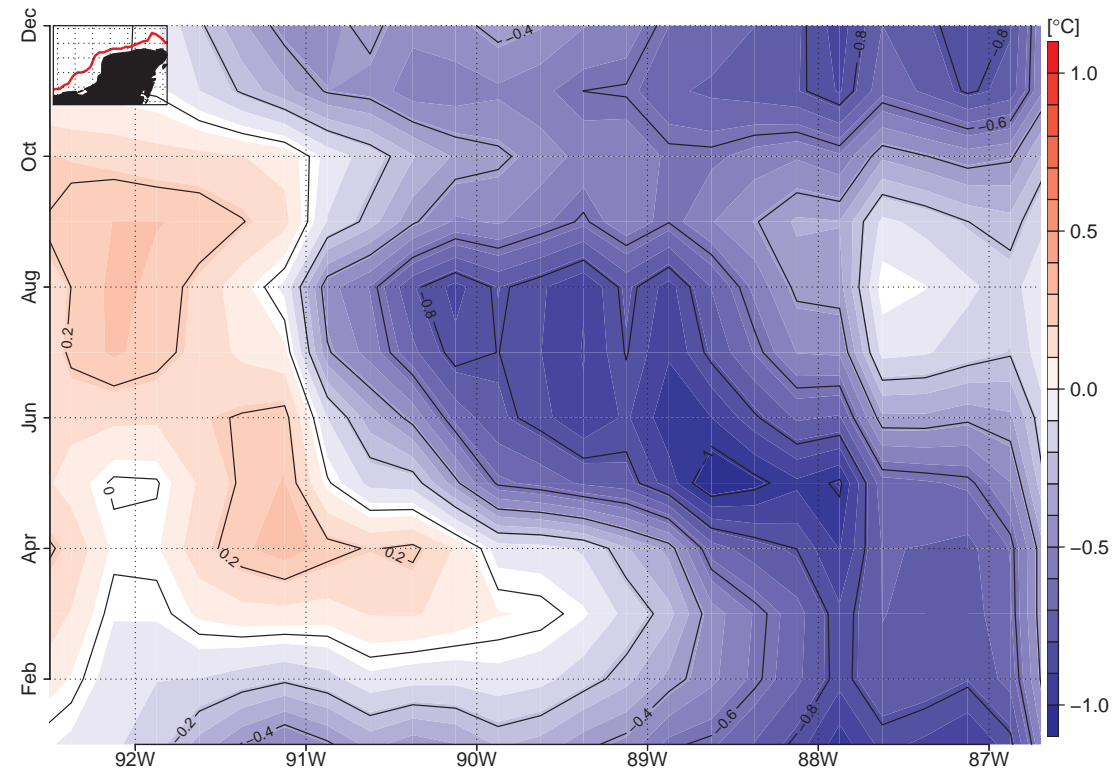

Figure 10: Hovmöller diagram of the monthly-averaged remotely sensed SST anomalies. Red (blue) color shows warmer (colder) temperatures than the 39 years spatial-temporal mean (1981-2020). Top left are the positions used for the calculations (in red).

Lagrangian results presented here are in agreement with the ensemble-mean Lagrangian circulation sustained by the instantaneous HyCOM-GOM10.04 velocity from 1994 through 2014, depicted for example in figure 1 of (Duran et al., 2018). In that figure, the ensemble-mean distribution of a passive tracer moves westward over the Yucatan shelf. The ensemble averaging is taken over different initial times spanning 1994-2014. Blue tracer reaches the furthest towards the west at the location where cLCS deform as chevrons towards 
the west, and where the climatological attraction is weakest. This is in excellent agreement with the 2018 trajectory simulation presented here, where trajectories originating in the Yucatan shelf move across cLCS where the climatological strength of attraction is weakest and where they deform as chevrons towards the west (Fig. 9). Thus, the existence of a predominant pathway connecting the eastern Yucatan shelf and the Bay of Campeche (western Yucatan shelf) becomes clear. Different experiments supporting a persistent along-slope Lagrangian link between the eastern and western Yucatan shelf, including the 2018 simulation presented here (Fig. 7), the ensemble-mean tracer distribution from an instantaneous velocity spanning 1994 through 2014 (Duran et al., 2018), and cLCS computed from a 1994-2014 climatological velocity (Duran et al., 2018). Trajectories computed directly from the climatological velocity are also in good agreement with this pattern, although when initiated in the Campeche pool of cool water and integrated backward in time, trajectories are closer to the coast, where strongly-attracting cLCS align with the coastline, thus confirming the cLCS's strong attraction (Fig. 9).

\section{Conclusions}

Upwelled waters off the Campeche coast are brought to the region recurrently by the southwestward peninsular currents from the Yucatecan coast, hundreds of kilometers away, being stronger during summer (from July to August each year). Although the region is wide open and very shallow, this phenomenon manages to separate the water column into two layers with differentiable thermohaline characteristics, both with Caribbean water-type signatures evidencing the high connectivity of the region.

More information is needed to address these interesting phenomena and improve our understanding of their role in the environment. The following are some of the issues that still remain open and would be interesting to address in future work: (1) the role that upwelled waters must play in the heat budget of the Yucatan shelf, that in spring and summer exhibits high atmospheric temperatures $\left(>35^{\circ} \mathrm{C}\right)$. (2) The interaction between these events and the Northerly cold wind burst phenomena, which also cools down the water temperature of the region. (3) The important implications they must have to the marine biota over the bank by bringing colder and nutrient-rich underwaters of Caribbean origin, to mention a few.

\section{Acknowledgments}

This work was possible thanks to the financial aid of CONACyT grants: Cátedras CONACyT (1912), Ciencia Básica (257075), Apoyo al Fortalecimiento y Desarrollo de la Infraestructura Científica y Tecnológica (270455). Special thanks to Gabriel May Uc, Julio Uc Medina and Heber Uc González for their fieldwork support in the oceanic surveys, and to the Instituto EPOMEX for all the facilities provided to carry out this work.

Funding for the development of HyCOM has been provided by the National Ocean Partnership Program and the Office of Naval Research. Data assimilative products using HyCOM are funded by the U.S. Navy. Computer time was made available by the DoD High-Performance Computing Modernization Program. The output is publicly available at https://hycom.org.

This project was funded by the United States Department of Energy, National Energy Technology Laboratory, in part, through a site support contract. Neither the United States Government nor any agency thereof, nor any of their employees, nor the support contractor, nor any of their employees, makes any warranty, express or implied, or assumes any legal liability or responsibility for the accuracy, completeness, or usefulness of any information, apparatus, product, or process disclosed or represents that its use would not infringe privately owned rights. Reference herein to any specific commercial product, process, or service by trade name, trademark, manufacturer, or otherwise does not necessarily constitute or imply its endorsement, recommendation, or favoring by the United States Government or any agency thereof. The views and opinions 
of authors expressed herein do not necessarily state or reflect those of the United States Government or any agency thereof.

\section{References}

Aldeco, J., Monreal, M.A., Signoret, M., Salas de León, D.A., Hernández, D.U., 2009. Occurrence of a subsurface anticyclonic eddy fronts, and Trichodesmium spp.. Ciencias Marinas 35, 333-344. https: //doi.org/10.7773/cm.v35i4.1551

Belousov, I.M., Ivanov, Y.A., Pasternak, S.A., Rass, T.S., Rossov, V.V., 1966. Oceanographic research by the Soviet-Cuban Marine Expedition. Oceanology 6, 312-320.

Bessonov, N., Gonzalez, O., Elizarov, A., 1971. Resultados de las investigaciones Cubano-Sovieticas en el Banco de Campeche, in: Coloquio Sobre Investigaciones y Recursos Del Mar Caribe y Regiones Adyacentes. UNESCO.

Bogdanov, D.V., Sokolov, V.A., Khromov, N.S., 1968. Regions of high biological and commercial productivity in the Gulf of Mexico and Caribbean Sea. Oceanology 8, 371-381.

Bulanienkov, S.K., Garcia, C., 1973. Influencia de los procesos atmosfericos en el afloramiento del Banco de Campeche, in: Cuarta Reunión De Balance De Trabajo, Centro De Investigaciones Pesqueras/Instituto NacionaI De La Pesca, Cuba, Informe De Investigación, 2, 28 Pp.

Cochrane, J.D., 1966. The Yucatan Current, upwelling off North-eastern Yucatan, and currents and waters of Western Equatorial Atlantic. Oceanography of the Gulf of Mexico. Progress Rep., TAMU, Ref No. 66-23T, pp. 14-32.

Cochrane, J.D., 1968. Currents and waters of the eastern Gulf of Mexico and western Caribbean, of the western tropical Atlantic Ocean, and of the eastern tropical Pacific Ocean.

Cochrane, J.D., 1969. Water and Circulation on Campeche Bank in May. Bull. Jpn. Soc. Fish. Oceanogr. Spec. No. (Prof. Uda's Commemorative Papers) 123-128.

Duran, R., Beron-Vera, F.J., Olascoaga, M.J., 2018. Extracting quasi-steady Lagrangian transport patterns from the ocean circulation: An application to the Gulf of Mexico. Scientific Reports 8. https://doi.org/ $10.1038 / \mathrm{s} 41598-018-23121-\mathrm{y}$

Duran, R., Beron-Vera, F.J., Olascoaga, M.J., 2019. CIAM Climatological Isolation and Attraction Model-Climatological Lagrangian Coherent Structures. National Energy Technology Laboratory-Energy Data eXchange; NETL. https://doi.org/https://doi.org/10.18141/1558781

Enriquez, C., Mariño-Tapia, I., Gilberto, J., Capurro-Filograsso, L., 2013. Thermohaline processes in a tropical coastal zone. Continental Shelf Research 69, 101-109. https://doi.org/10.1016/j.csr.2013. 08.018

Furnas, M.J., Smayda, T.J., 1987. Inputs of subthermocline waters and nitrate onto the Campeche Bank. Continental Shelf Research 7, 161-175. https://doi.org/https://doi.org/10.1016/02784343 (87) $90077-\mathrm{X}$

Gough, M.K., Beron-Vera, F.J., Olascoaga, M.J., Sheinbaum, J., Jouanno, J., Duran, R., 2019. Persistent Lagrangian Transport Patterns in the Northwestern Gulf of Mexico. Journal of Physical Oceanography 49, 353-367. https://doi.org/10.1175/jpo-d-17-0207.1

Gouveia, M.B., Duran, R., Lorenzzetti, J.A., Assireu, A.T., Toste, R., de F. Assad, L.P., Gherardi, D.F.M., 2021. Persistent meanders and eddies lead to quasi-steady Lagrangian transport patterns in a weak western boundary current. Scientific Reports 11. https://doi.org/10.1038/s41598-020-79386-9 
Haller, G., 2015. Lagrangian Coherent Structures. Annual Review of Fluid Mechanics 47, 137-162. https : //doi.org/10.1146/annurev-fluid-010313-141322

Herrera-Silveira, J.A., Medina-Gomez, I., Colli, R., 2002. Trophic status based on nutrient concentration scales and primary producers community of tropical coastal lagoons influenced by groundwater discharges. Hydrobiologia 475 .

Jouanno, J., Pallàs-Sanz, E., Sheinbaum, J., 2018. Variability and Dynamics of the Yucatan Upwelling: High-Resolution Simulations. Journal of Geophysical Research: Oceans 123, 1251-1262. https://doi.org/ $10.1002 / 2017 j \mathrm{j} 013535$

Kurczyn, J.A., Appendini, C.M., Beier, E., Sosa-López, A., López-González, J., Posada-Vanegas, G., 2020. Oceanic and atmospheric impact of central American cold surges (Nortes) in the Gulf of Mexico. International Journal of Climatology 41, E1450-E1468. https://doi.org/https://doi.org/10.1002/joc.6779

Martínez-López, B., Pares-Sierra, A., 1998. Circulation in the gulf of mexico induced by tides wind and the yucatan current. Ciencias Marinas 24,65-93. https://doi.org/10.7773/cm.v24i1.740

Maslo, A., de Souza, J.M.A.C., Andrade-Canto, F., Outerelo, J.R., 2020. Connectivity of deep waters in the Gulf of Mexico. Journal of Marine Systems 203, 103267. https://doi.org/10.1016/j .jmarsys. 2019. 103267

McDougall, T.J., Barker, P.M., 2011. Getting started with TEOS-10 and the Gibbs Seawater (GSW) Oceanographic Toolbox. SCOR/IAPSO WG127 28.

Merino, M., 1997. Upwelling on the Yucatan Shelf: hydrographic evidence. Journal of Marine Systems 13, 101-121. https://doi.org/10.1016/s0924-7963(96)00123-6

Molinari, R.L., 1980. Current variability and its relation to sea-surface topography in the Caribbean Sea and Gulf of Mexico. Marine Geodesy 3.

Nordam, T., Duran, R., 2020. Numerical integrators for Lagrangian oceanography. Geoscientific Model Development 13. https://doi.org/10.5194/gmd-13-5935-2020

Nowlin, W.D., Mclellan, H.J., 1967. A Characterization Of The Gulf Of Mexico Waters In Winter. Journal of Marine Research 25, 29-59.

RCoreTeam, 2014. R: A language and environment for statistical computing. R Foundation for Statistical Computing. Vienna, Austria.

Reyes-Mendoza, O., Herrera-Silveira, J., Mariño-Tapia, I., Enriquez, C., Largier, J.L., 2019. Phytoplankton blooms associated with upwelling at Cabo Catoche. Continental Shelf Research 174.

Reyes-Mendoza, O., Mariño-Tapia, I., Herrera-Silveira, J., Ruiz-Martínez, G., Enriquez, C., Largier, J.L., 2016. The Effects of Wind on Upwelling off Cabo Catoche. Journal of Coastal Research 32.

Reynolds, R.W., Rayner, N.A., Smith, T.M., Stokes, D.C., Wang, W., 2002. An Improved In Situ and Satellite SST Analysis for Climate. Journal of Climate 15, 1609-1625. https://doi.org/10.1175/15200442 (2002) $015<1609:$ AIISAS $>2$. 0. CO ; 2

Ruiz-Renteria, F., 1979. Upwelling North of the Yucatan Peninsula (Master's thesis). Texas A\&M University.

Ruíz-Castillo, E., Gomez-Valdés, J., Sheinbaum, J., Rioja-Nieto, R., 2016. Wind-driven coastal upwelling and westward circulation in the Yucatan shelf. Continental Shelf Research 118.

Troupin, C., Barth, A., Sirjacobs, D., Ouberdous, M., Brankart, J.M., Brasseur, P., Rixen, M., AlveraAzcárate, A., Belounis, M., Capet, A., Lenartz, F., Toussaint, M.E., Beckers, J.M., 2012. Generation of analysis and consistent error fields using the Data Interpolating Variational Analysis (DIVA). Ocean Modelling 52-53, 90-101. https://doi.org/10.1016/j.ocemod.2012.05.002 
Valle-Levinson, A., Mariño-Tapia, I., Enriquez, C., Waterhouse, A.M., 2011. Tidal variability of salinity and velocity fields related to intense point-source submarine groundwater discharges into the coastal ocean. Limnology and Oceanography 56, 1213-1224. https://doi.org/https://doi.org/10.4319/1o.2011.56. 4.1213

Vidal, V.M.V., Vidal, F.V., Hernández, A.F., Meza, E., Zambrano, L., 1994. Winter water mass distributions in the western Gulf of Mexico affected by a colliding anticyclonic ring. Journal of Oceanography 50, 559-588. https://doi.org/10.1007/bf02235424

Zavala-Hidalgo, J., Morey, S.L., O'Brien, J.J., 2003. Seasonal circulation on the western shelf of the Gulf of Mexico using a high-resolution numerical model. Journal of Geophysical Research 108. https://doi.org/ 10.1029/2003jc001879 